\title{
Treatment of enemy wounded: evidence from the No. 7 Canadian Stationary Hospital (Dalhousie University)
}

\author{
Desmond Leddin, MB \\ Paul Charlebois, MD
}

Accepted Dec. 20, 2016.

\author{
Correspondence to: \\ D. Leddin \\ Room 912 Victoria \\ Victoria General Hospital \\ 1278 Tower Rd \\ Halifax NS B3H 2 Y9 \\ Desmond.Leddin@dal.ca
}

DOI: $10.1503 /$ cjs. 016716

\section{SUMMARY}

Dalhousie University, with the help of the other Maritime universities formed and sent a hospital to Europe during the First World War (WWI). They served from January 1916 to April 1919. There is no comprehensive account of the treatment of German wounded by Canadian Medical Services in WWI; however, there is direct photographic and written evidence from the No. 7 Canadian Stationary Hospital that the relationship was one of mutual trust, more characteristic of that between a health care provider and patient than between combatants. The activities of the No. 7 in treating German wounded from the Western Front provide insight into this undocumented aspect of the medical services in WWI. A previously unrecognized painting by Sir William Orpen, one of the leading artists of the 20th century, of the unit at work in France is described. An appendix to this commentary is available at canjsurg.ca.

n December 1915 the No. 7 Canadian Stationary Hospital (Dalhousie University) formed for the first time on the grounds where Dalhousie Medical School now stands. The 165 -strong unit was composed of surgeons, physicians, a pharmacist and 27 nurses. The majority of the unit comprised nonmedical support staff. Following a 6-month stay in England, they crossed to France in June 1916 where they were involved in the care of both German and Allied wounded until their repatriation in 1919 (Appendix 1, available at canjsurg.ca). ${ }^{1}$

On the Western Front where the No. 7 served, 1.5 million German soldiers were killed, 2.6 million wounded and 750000 captured. ${ }^{2}$ Inevitably some of the captured soldiers were wounded and required medical care.

The official history of the Canadian Medical Services does mention the care of German wounded, but there is no comprehensive account. ${ }^{3}$ The experience of the No. 7, which has been documented in their war diary, letters home, photographs and in other materials that have survived, provides insight into how German wounded were treated by a Canadian hospital in France.

We do not know how the staff of the No. 7 felt about treating combatant wounded before they actually encountered them. The only insight we have is from a collection of postcards, now in the Dalhousie libraries, that were sent back from one of the support staff, Fraser Tupper, to his nephew in Halifax. They reflect the anti-German feeling of the time, and he advises his nephew, "you must not love the Germans for they are very bad people even if they live in Nova Scotia." Whether that attitude was pervasive among the medical staff is not known, but likely there was a range of emotions.

In May 1917 the unit moved to the village of Arques in northwest France. While there, they regularly received wounded soldiers, including Germans, from the battlefield around Ypres and Messine. The war diary is a terse administrative document and does not record the tone of the interaction between the No. 7 staff and former combatants.

Dr. John Stewart was the commanding officer of the unit. At age 67 he had respect and stamina. While travelling in Europe in his younger days he had 


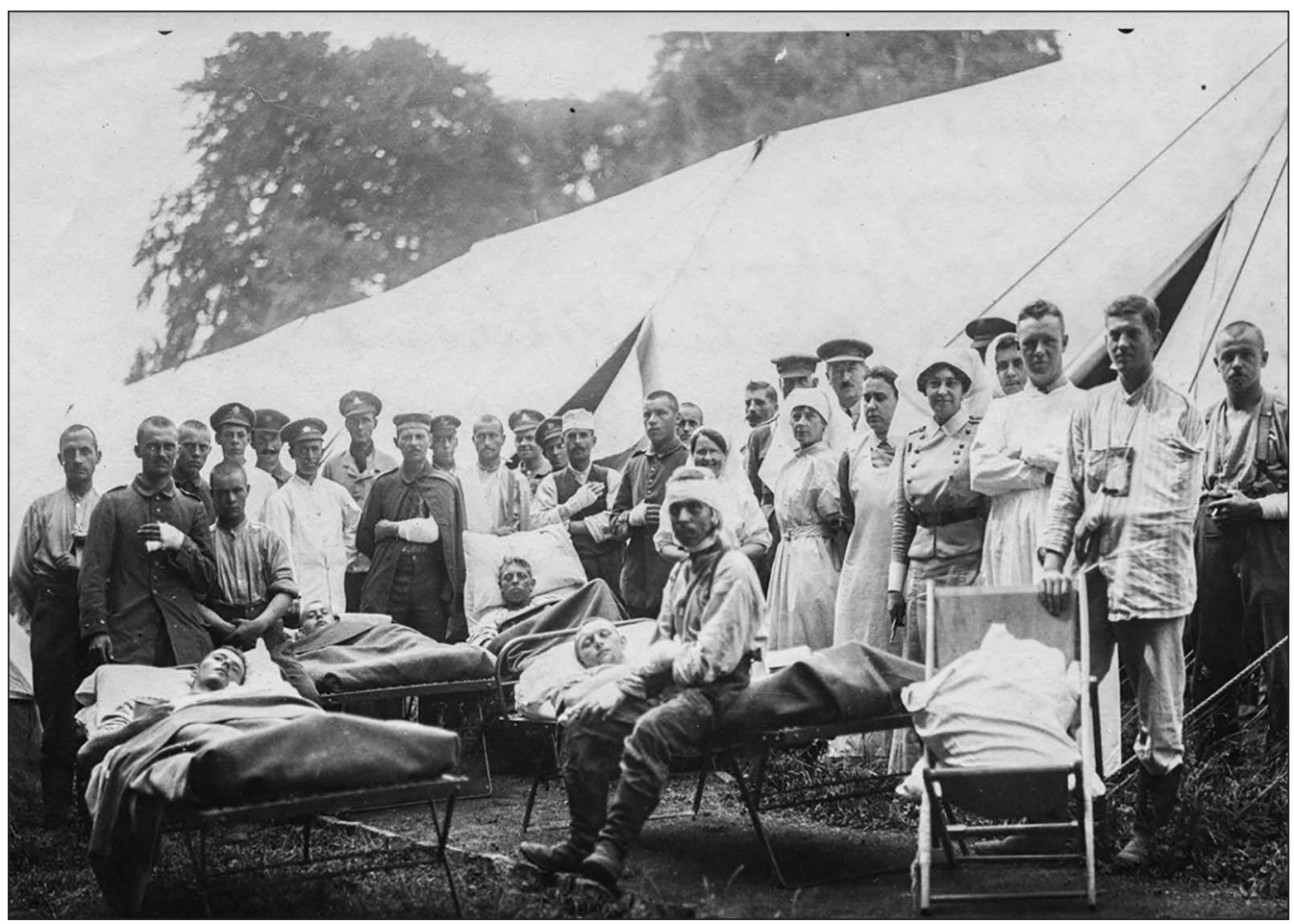

German wounded with Dalhousie medical and nursing staff. June 1917, Arques, France. Dalhousie archives.

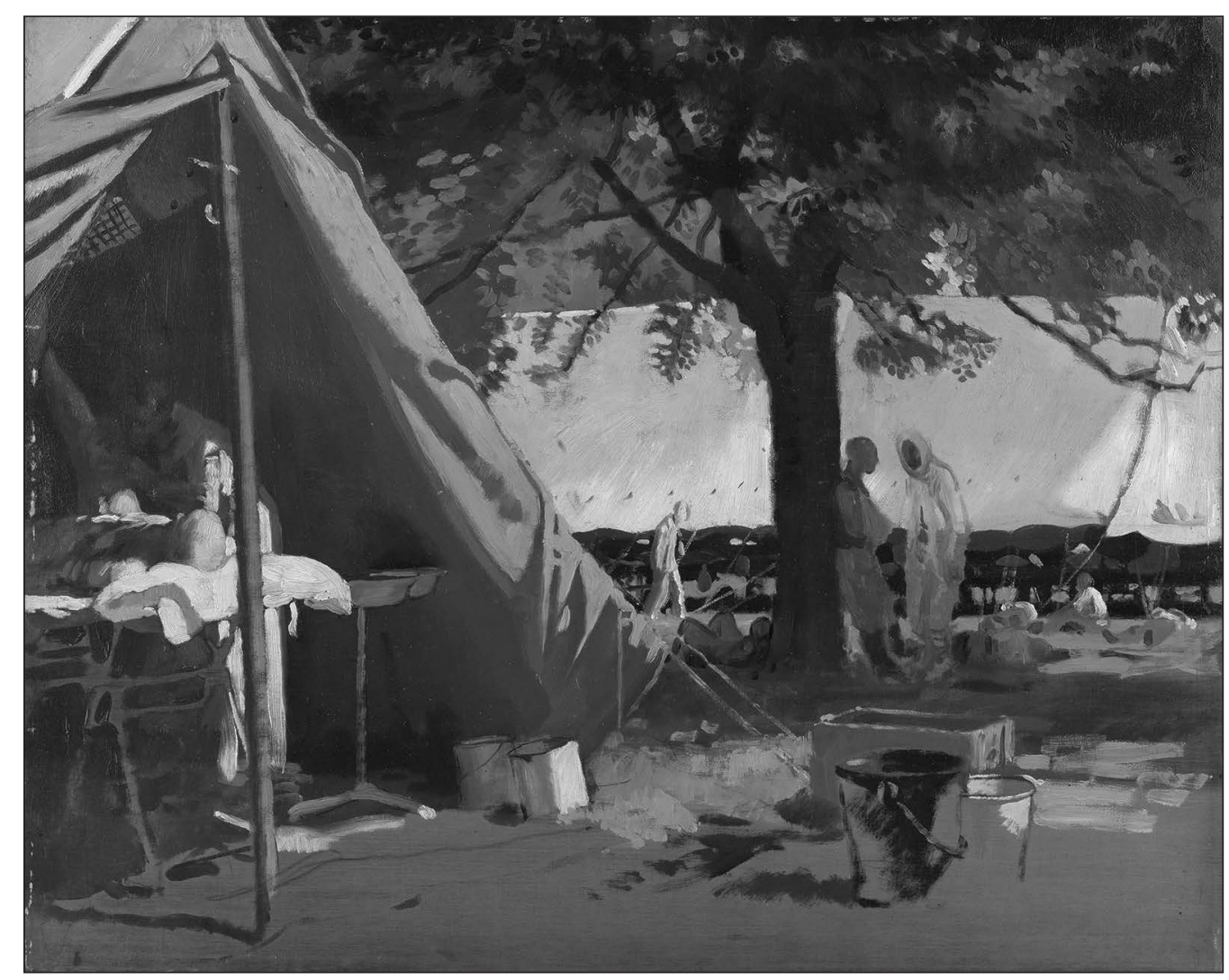

William Orpen's painting "German Sick, Captured at Messines, in a Canadian Hospital." Imperial War Museum IWM ART 3043. Reproduced with permission from the IWM. 
learned German and was able to converse with the wounded enemy soldiers. Stewart wrote home regularly, and in one of his letters to the Dalhousie newspaper he gave an account of a small gesture of kindness to a German captive. A Christmas tree with a German flag sent to the captive by his girlfriend was allowed on the dining table a small gesture, but a definite message to the more bellicose home front.

We also have some idea of how the Germans may have felt about their captors. A scrapbook kept by one of the Dalhousie nurses has survived. There are 80 pages of photographs, poems, flowers and locks of hair from wounded soldiers. Tucked away on one page is a field postcard from one of the Germans thanking the sister for the gift of strawberries, which might suggest that relations were cordial.

More direct evidence of the interaction comes from the photographic record. A number of images of the hospital at Arques have been preserved, and in those photographs are several of the hospital medical and nursing staff posing with German wounded, with no suggestion of antagonism from either side. There are no guards, and they look perfectly comfortable in each other's company. It is fair to assume that once a wounded combatant reached the care of the rear line Canadian Medical Services that both sides adopted a patient-health care provider relationship and left the war at the front lines.

In June 1917, the hospital had a visit from the war artist, Sir William Orpen. He was born in Dublin in 1878 and became one of the greatest British painters of the early 20th century. His work is in many national galleries as well as the Musée d'Orsay in Paris and the Tate Gallery in London. Orpen joined the British army in December 1915 and went to France as an official British war artist in April 1917. After the war Orpen donated 144 of his war works to the British nation and published a diary of his wartime experience. One painting of a hospital in France, now in the Imperial War Museum, shows a wounded soldier being treated in a tent while others talk and rest.

The title of the painting "German Sick, Captured at Messines, in a Canadian Hospital," the known situation of the Dalhousie hospital, the war diaries of other Canadian hospitals and the timing of Orpen's visit make it reasonably certain that the painting, not previously ascribed to a particular Canadian unit, portrays the Dalhousie Stationary hospital in the village of Arques, France, in June 1917. ${ }^{1}$ The mood of the painting mirrors that from the photograph of the German wounded with the Dalhousie medical and nursing staff; some wounded are being treated, others chat in the shade of a tree. There is no sense of urgency or antagonism. It is not a very war-like scene and likely captures the mood between captives and medical personnel very well.
The evidence that we have from the work of the No. 7 indicates that wounded enemy combatants in WWI were well treated by the Canadian Medical Services. Once the enemy made the transition from combatant to patient, the war was left behind and care was given to German wounded in the same manner as it was to Canadians.

The care given to the German combatants by the No. 7 would have been governed by the earlier iterations of the Geneva Conventions (1864 and 1906), whereas currently the care of wounded adversaries is covered by the Geneva Convention of $1949 .{ }^{4}$ As the practices of modern warfare have changed over the last 2 centuries, the Geneva Conventions have had to be continuously reviewed and revised to ensure their relevance and ability to cope with changing technologies and tactics.

During Canada's time managing the Role 3 Multinational Medical Unit in Kandahar, Afghanistan, detainees were treated with the same high level of medical care that was offered to all of our patients. The interactions were not as informal as they appeared to be during the time of the No. 7. Strict protocols involving security and the segregation of detainees were in place to ensure the safety of both staff and patients. Unlike, Dr. Stewart's knowledge of German, many of us had only had rudimentary knowledge of Dari or Pashtun, and thus we relied on local language experts for both communication and social context. Also unlike the experience of the No. 7, our adversaries were from a cultural background that was vastly different from that of Canada in many aspects. That being said, the basic human tenets of kindness and compassion are universal, and many of the detainees we treated were appreciative of the care received, and many reacted with gratitude toward the hospital staff.

Affiliations: From the Department of Medicine, Dalhousie University, Halifax, NS (Leddin, Charlebois); the Canadian Field Hospital, Petawawa, ON (Charlebois); and the Canadian Forces Health Services Centre (Atlantic), Halifax, NS (Charlebois).

Competing interests: None declared.

Contributors: Both authors contributed substantially to the conception, writing and revision of this article and approved the final version for publication.

\section{References}

1. Leddin D. The No. 7 Canadian Stationary Hospital (Dalhousie University) in World War One. Skibbereen, Co. Cork, Ireland Redbarn; 2015.

2. Ellis J, Cox M. The World War I data book. London (UK): Aurum Press; 1993.

3. MacPhail A. Official history of the Canadian forces in the great war 191419: The medical services. Ottawa (ON): F. A. Acland, King's Printer; 1925.

4. Article 12, First Geneva Convention of 1949 (2016 Commentary), International Committee of the Red Cross, Geneva. 